\title{
Prognostic impact of maximum standardized uptake value (SUVmax) of the primary lesion on survival in advanced non-small-cell lung cancer: A retrospective study
}

\section{Xiaoling Qiu}

University of Hong Kong-Shenzhen Hospital

Hongge Liang

Peking University People's Hospital

\section{Wei Zhong}

Peking Union Medical College Hospital

Jing Zhao

Peking Union Medical College Hospital

Minjiang Chen

Peking Union Medical College Hospital

Zhaohui Zhu

Peking Union Medical College Hospital

\section{Yan Xu ( $\nabla$ maraxu@163.com )}

Peking Union Medical College Hospital https://orcid.org/0000-0002-2832-2664

\section{Mengzhao Wang}

Peking Union Medical College Hospital

\section{Research article}

Keywords: Epidermal growth factor receptor; Non-small-cell lung cancer; Positron-Emission Tomography;

Prognosis; SUVmax

Posted Date: July 17th, 2020

DOI: https://doi.org/10.21203/rs.3.rs-41522/v1

License: (c) (i) This work is licensed under a Creative Commons Attribution 4.0 International License. Read Full License 


\section{Abstract}

Background: Positron emission tomography/computed tomography (PET/CT) has been widely recognized for diagnosing and staging lung cancer, but the prognostic value of standardized uptake value (SUV) in patients with advanced non-small-cell lung cancer (NSCLC) remains controversial. We aim to explore whether fluorodeoxyglucose uptake has prognostic significance in patients with advanced NSCLC.

Methods: We performed a retrospective analysis of the data of patients with advanced NSCLC who had undergone PET/CT before systemic treatment between June 2012 and June 2016. The relationship between the SUV of the pulmonary lesion and lesion size was evaluated via Spearman's correlation analysis. We collected patients' clinical and pathological data. Univariate and multivariate analyses were performed to analyze the factors influencing survival.

Results: Altogether, 157 patients with advanced NSCLC were included. Among these, 135 died, 13 survived, and 9 had incomplete data (median follow-up period of 69 months). SUV was correlated with lesion size and was significantly greater for tumors $\geq 3 \mathrm{~cm}$ than for tumors $<3 \mathrm{~cm}(10.2 \pm 5.4$ vs. $5.6 \pm 3.3, t=-6.709$, $p=0.000$ ). Univariate analysis showed that survival was associated with gender, tumor size, epidermal growth factor receptor (EGFR) gene mutation, SUV of the primary lung lesion, and treatment line.

Multivariate analysis showed a significant correlation between SUV of the primary lung lesion and survival. The mortality risk of patients with SUV $\leq 6$ was $35 \%$ lower than that of patients with SUV $>6(95 \% \mathrm{Cl} 0.436$ 0.972 , Wald value $4.400, p=0.036$ ).

Conclusions: The SUV of the primary lung lesion on PET/CT is significantly correlated with survival in previously untreated patients newly diagnosed with advanced NSCLC.

\section{Background}

Lung cancer is a leading cause of cancer-related death worldwide in both men and women. The most common type of lung cancer is non-small-cell lung cancer (NSCLC), which accounts for $80 \%$ of all cases[1]. Most patients with advanced NSCLC are diagnosed at a late stage and are thus no longer eligible for radical surgery. Accordingly, the 5 -year overall survival rate of patients with advanced lung cancer is only $9-13 \%[2$, 3]. Several potential prognostic factors for NSCLC are currently recognized, such as sex, disease stage, physical status[4, 5], liver or skin metastases, and driver genes.

Fluorine-18 fluorodeoxyglucose (FDG) positron-emission tomography/computed tomography (PET/CT) is based on the metabolism[6, 7]and glucose uptake ability of the majority of malignant tumors[2, 5, 8]. The standardized uptake value (SUV) is a semiquantitative measurement of the FDG uptake in tissues.

Accordingly, it can be used to evaluate tumor metabolic activity[9-11]. Several studies have shown a high sensitivity,specificity, and accuracy of PET/CT for diagnosis,staging[2-4, 12],post-therapy assessment, and outcome prediction $[2,4,7,8,10,11,13-19]$ as well as its utility as an accurate and non-invasive modality in clinical practice. However, the methods in these studies differ and their conclusions are not completely consistent $[12,20,21]$. Furthermore, the utility of SUV for predicting survival in advanced NSCLC requires 
further study. Thus, in this study, we aim to explore the prognostic value of FDG PET/CT in patients with advanced NSCLC.

\section{Methods}

\section{Patient Population}

The subjects were 269 patients who underwent PET/CT imaging between June 2012 and June 2016 at Peking Union Medical College Hospital, China. The patients were identified from the hospital's PET/CT center patient database and the Lung Cancer Centre patient database. The inclusion criteria were as follows: (a) histologically/cytologically confirmed stage IV disease, (b) ineligibility to undergo radical surgery and radiotherapy, (c) no prior systemic therapy before PET/CT, (d) received systemic treatment within 6 weeks after PET/CT assessment, and (e) consent to follow-up. The exclusion criteria were (a) small-cell lung cancer, metastatic lung cancer, and other rare lung cancers or other cancer in the past 5 years; (b) stage I-III NSCLC; (c) without complete evaluation; (d) without systemic treatment. Altogether, 157 patients were included in the study. The patient selection flowchart is shown in Fig. 1.

The study was approved by Ethics Committee of Peking Union Medical College Hospital. We collected data on the patients' demographic characteristics, including sex and age. Clinical data, such as the patients' smoking history, weight loss, performance status (PS) score, tumor/node/metastasis (TNM) stage, number, and location of metastatic lesions, treatment line, and follow-up, were also collected. We also recorded the histopathologic characteristics of lung cancer, including their gene signatures, histology, and the presence of epidermal growth factor receptor (EGFR) mutations. Lastly, we considered the patients' PET/CT data, such as their lung lesion size as well as the SUVmax of the primary lung lesion and metastatic lesions. Patients were followed up for a median of 69 months (range, 2-83 months). The last follow-up was in June 2018.

Overall survival was defined as the time between diagnosis and the last follow-up or death. The median age at diagnosis was 65 years, which was used as a boundary value to divide the patients into two groups. Staging was performed according to the International Association for the Study of Lung Cancer (IASCL) TNM staging system, 7th edition. Loss of weight was defined as a 10\% decline in weight within the past 6 months. The size of the primary lung lesion was determined according to the maximum diameter of the lesion. With respect to SUVmax, both the primary lung lesion and the metastatic lesions were included. Brain metastases were not counted, as PET/CT has a low sensitivity for brain metastases. For example, in this study, 33 patients had brain metastases, but only 14 of them were diagnosed via PET/CT. Treatment was divided into two types: first-line treatment and second-line treatment or above. Because EGFR mutation testing, but not anaplastic lymphoma kinase (ALK) and c-ros oncogene 1 receptor tyrosine kinase (ROS1) gene testing, was already routinely performed during the study period, only the EGFR gene mutation was evaluated. In total, 51 patients with positive EGFR gene mutation received first-line EGFR tyrosine kinase inhibitor (TKI) treatment, 106 patients received platinum-containing combination chemotherapy, and 39 patients received treatment combined with bevacizumab, while 81 patients received second-line treatment after progression. 


\section{Data analysis}

All statistical analyses were performed using IBM SPSS Statistics 25 (Armonk, New York, USA). An independent sample t-test was performed to explore the association between the SUVmax of the primary lung lesion or the highest SUVmax among all lesions and survival. Likewise, the differences in SUVmax between the primary lung lesion and metastatic lesion were compared using this method. The SUVs were categorized into the following ranges: $0-2,2-4,4-6,6-8,8-10,10-12,12-14$, and $>14$. Survival curves were drawn to define an optimal cut-off value, and SUVs were then divided into two groups according to the cut-off. Survival differences between these two groups were then evaluated using the Kaplan-Meier method. We also analyzed the survival impact of various factors, including sex, age, smoking status, loss of weight, performance status (PS) score, lung lesion size, smoking histology, EGFR mutation, TNM staging, number and location of metastatic lesions, treatment line, and SUVmax of the lung lesion.

Spearman's correlation analysis was used to investigate significant relationships between the SUVmax of the primary lung lesion and tumor size. Univariate survival analysis was performed using the Kaplan-Meier method, and comparison of survival between groups was performed using the log-rank test. Multivariate analysis was performed using the Cox proportional hazards model. Hazard ratios (HR) with $95 \%$ confidence intervals $(\mathrm{Cl})$ were equally calculated. A p value of $<0.05$ was considered significant.

\section{Results}

\section{Correlation between patients' clinical characteristics and SUVmax}

Altogether, 157 advanced NSCLC patients were included. Among these patients, 135(86\%) died, 13 (8\%) survived, and 9 had incomplete follow-up data. The correlation between the patients' clinical characteristics and the SUVmax of the primary lung lesions as well as the highest SUVmax among all lesions is shown in Table 1. 
Table 1

Correlation between patients' clinical characteristics and SUVmax

\begin{tabular}{|c|c|c|c|c|c|c|c|c|}
\hline Variable & & No. & $\begin{array}{l}\text { SUV of } \\
\text { primarylung } \\
\text { lesion }\end{array}$ & $\begin{array}{l}\mathrm{t} \\
\text { value }\end{array}$ & $\begin{array}{l}P \\
\text { value }\end{array}$ & $\begin{array}{l}\text { highestSUV } \\
\text { of all } \\
\text { lesions }\end{array}$ & $\begin{array}{l}t \\
\text { value }\end{array}$ & $\begin{array}{l}\mathrm{P} \\
\text { value }\end{array}$ \\
\hline \multirow[t]{2}{*}{ age } & $\geq 65$ & 71 & $9.1 \pm 6.1$ & 1.542 & 0.126 & $10.1 \pm 6.1$ & 0.555 & 0.58 \\
\hline & $\varangle 65$ & 86 & $7.8 \pm 4.3$ & & & $9.6 \pm 4.5$ & & \\
\hline \multirow[t]{2}{*}{ sex } & male & 98 & $8.1 \pm 5.3$ & 0.979 & 0.329 & $9.9 \pm 5.6$ & 0.456 & 0.649 \\
\hline & female & 59 & $8.9 \pm 4.9$ & & & $9.5 \pm 4.8$ & & \\
\hline \multirow{2}{*}{$\begin{array}{l}\text { smoking } \\
\text { history }\end{array}$} & yes & 63 & $8.1 \pm 5.1$ & 0.532 & 0.595 & $10.2 \pm 5.6$ & -0.699 & 0.486 \\
\hline & no & 94 & $8.6 \pm 5.2$ & & & $9.6 \pm 5.1$ & & \\
\hline \multirow[t]{2}{*}{ weight loss } & yes & 22 & $9.4 \pm 5.5$ & 0.945 & 0.346 & $12 \pm 5.1$ & 2.079 & 0.039 \\
\hline & no & 135 & $8.2 \pm 5.1$ & & & $9.6 \pm 5.3$ & & \\
\hline \multirow[t]{2}{*}{ PS score } & $0-1$ & 146 & $8.6 \pm 5.2$ & 1.774 & 0.078 & $9.8 \pm 5.3$ & 0.276 & 0.783 \\
\hline & $\geq 2$ & 11 & $5.7 \pm 3.6$ & & & $9.4 \pm 5.0$ & & \\
\hline \multirow[t]{2}{*}{ lesion size } & $\geq 3 \mathrm{~cm}$ & 95 & $10.2 \pm 5.4$ & 6.709 & 0 & $11.2 \pm 5.5$ & 4.754 & 0 \\
\hline & $\unrhd 3 \mathrm{~cm}$ & 61 & $5.6 \pm 3.3$ & & & $7.6 \pm 4.1$ & & \\
\hline \multirow[t]{2}{*}{ histology } & squamous & 20 & $9.8 \pm 6.8$ & 0.995 & 0.33 & $12.1 \pm 6.1$ & 2.092 & 0.038 \\
\hline & $\begin{array}{l}\text { Non- } \\
\text { squamous }\end{array}$ & 137 & $8.2 \pm 4.9$ & & & $9.5 \pm 5.1$ & & \\
\hline \multirow[t]{2}{*}{ EGFR mutation } & yes & 51 & $7.9 \pm 4.8$ & 0.848 & 0.398 & $9.0 \pm 4.6$ & 1.257 & 0.211 \\
\hline & no & 106 & $8.6 \pm 5.4$ & & & $10.2 \pm 5.6$ & & \\
\hline \multirow[t]{2}{*}{ TMN stage } & M1a & 38 & $8.4 \pm 3.8$ & 0.064 & 0.063 & $8.8 \pm 4.4$ & -1.315 & 0.094 \\
\hline & M1b & 119 & $8.4 \pm 5.6$ & & & $10.1 \pm 5.5$ & & \\
\hline \multirow{2}{*}{$\begin{array}{l}\text { bone } \\
\text { metastasis }\end{array}$} & yes & 99 & $8.1 \pm 5.4$ & 0.897 & 0.371 & $9.6 \pm 5.3$ & 0.627 & 0.532 \\
\hline & no & 58 & $8.9 \pm 4.8$ & & & $10.2 \pm 5.3$ & & \\
\hline \multirow{2}{*}{$\begin{array}{l}\text { adrenal } \\
\text { metastasis }\end{array}$} & yes & 32 & $9.2 \pm 6.3$ & 0.838 & 0.407 & $11.0 \pm 5.6$ & 1.461 & 0.146 \\
\hline & no & 125 & $8.2 \pm 4.9$ & & & $9.5 \pm 5.2$ & & \\
\hline
\end{tabular}




\begin{tabular}{|c|c|c|c|c|c|c|c|c|}
\hline Variable & & No. & $\begin{array}{l}\text { SUV of } \\
\text { primarylung } \\
\text { lesion }\end{array}$ & $\begin{array}{l}\mathrm{t} \\
\text { value }\end{array}$ & $\begin{array}{l}P \\
\text { value }\end{array}$ & $\begin{array}{l}\text { highestSUV } \\
\text { of all } \\
\text { lesions }\end{array}$ & $\begin{array}{l}\mathrm{t} \\
\text { value }\end{array}$ & $\begin{array}{l}P \\
\text { value }\end{array}$ \\
\hline \multirow{2}{*}{$\begin{array}{l}\text { pleura } \\
\text { metastasis }\end{array}$} & yes & 49 & $9.0 \pm 5.6$ & 1.046 & 0.297 & $10.0 \pm 5.7$ & 0.307 & 0.759 \\
\hline & no & 106 & $8.1 \pm 5.0$ & & & $9.7 \pm 5.2$ & & \\
\hline \multirow{2}{*}{$\begin{array}{l}\text { lymph node } \\
\text { metastasis }\end{array}$} & yes & 102 & $8.9 \pm 5.3$ & 1.671 & 0.097 & $9.8 \pm 5.5$ & 0.025 & 0.98 \\
\hline & no & 55 & $7.5 \pm 4.8$ & & & $9.8 \pm 4.9$ & & \\
\hline \multirow{2}{*}{$\begin{array}{l}\text { liver } \\
\text { metastasis }\end{array}$} & yes & 18 & $10.1 \pm 6.2$ & 1.471 & 0.143 & $10.9 \pm 5.7$ & 0.952 & 0.342 \\
\hline & no & 139 & $8.2 \pm 5.0$ & & & $9.7 \pm 5.2$ & & \\
\hline \multirow{2}{*}{$\begin{array}{l}\text { intrapulmonary } \\
\text { metastasis }\end{array}$} & yes & 51 & $9.3 \pm 5.1$ & 1.622 & 0.107 & $10.0 \pm 4.9$ & 0.359 & 0.72 \\
\hline & no & 105 & $7.9 \pm 5.2$ & & & $9.7 \pm 5.5$ & & \\
\hline \multirow{2}{*}{$\begin{array}{l}\text { metastatic } \\
\text { numbers }\end{array}$} & $\geq 2$ & 78 & $8.9 \pm 5.8$ & 1.47 & 0.145 & $10.7 \pm 5.5$ & 2.413 & 0.017 \\
\hline & $\otimes 2$ & 77 & $7.7 \pm 4.1$ & & & $8.7 \pm 4.7$ & & \\
\hline \multirow[t]{2}{*}{ treatment line } & first-line & 76 & $9.3 \pm 5.5$ & 2.227 & 0.027 & $10.5 \pm 5.5$ & 1.566 & 0.119 \\
\hline & $\begin{array}{l}\text { second- } \\
\text { line }\end{array}$ & 81 & $7.5 \pm 4.7$ & & & $9.2 \pm 4.7$ & & \\
\hline \multirow{2}{*}{$\begin{array}{l}\text { SUV of } \\
\text { metastatic } \\
\text { lesion higher } \\
\text { than primary } \\
\text { lung lesion }\end{array}$} & yes & 44 & $4.8 \pm 3.4$ & 6.018 & 0 & $9.5 \pm 5.5$ & 0.412 & 0.681 \\
\hline & no & 113 & $9.8 \pm 5.1$ & & & $9.9 \pm 5.2$ & & \\
\hline
\end{tabular}

The SUVmax of the primary lung lesions was significantly correlated with tumor size. Tumors $\geq 3 \mathrm{~cm}$ in size had a significantly greater SUVmax than did tumors $<3 \mathrm{~cm}$ in size $(10.2 \pm 5.4$ vs. $5.6 \pm 3.3, t=-6.709, p=$ 0.000). The SUVmax of primary lung lesions was also associated with treatment line. The SUVmax for patients receiving first-line treatment was significantly greater than that for those receiving second-line treatment or above. The factors related to the highest SUVmax among all lesions included loss of weight, lung lesion size, histology, EGFR mutation, and number of metastases. The highest SUV among all lesions significantly increased in patients with a lower body weight, lung lesion size $\geq 3 \mathrm{~cm}$, squamous cell carcinoma, and number of metastases $\geq 2$. 
The SUV of the primary lung lesions was significantly higher than that of the metastatic lesions (pष0.05) (Table 2). Further, the SUVmax of the primary lung lesions could better reflect the severity of the tumor $(\mathrm{p} \otimes 0.05)$.

Table 2

Comparison between the SUV of primary lung lesions and metastatic lesions

\begin{tabular}{|lcllll|}
\hline metastatic lesions & No. & $\begin{array}{l}\text { SUV of metastatic } \\
\text { Lesion }\end{array}$ & $\begin{array}{l}\text { SUV of Lung } \\
\text { cancerlesion }\end{array}$ & $\begin{array}{l}\mathbf{t} \\
\text { value }\end{array}$ & $\begin{array}{l}\mathbf{P} \\
\text { value }\end{array}$ \\
\hline bone & 99 & $6.0 \pm 4.1$ & $8.1 \pm 5.4$ & -3.124 & 0.002 \\
\hline adrenal & 32 & $5.3 \pm 4.5$ & $9.2 \pm 6.3$ & -2.872 & 0.006 \\
\hline pleura & 50 & $4.8 \pm 4.3$ & $9.0 \pm 5.5$ & -4.222 & 0 \\
\hline $\begin{array}{l}\text { mediastinal lymph } \\
\text { nodes }\end{array}$ & 101 & $6.0 \pm 3.7$ & $8.8 \pm 5.3$ & -4.37 & 0 \\
\hline $\begin{array}{l}\text { liver } \\
\text { intrapulmonary }\end{array}$ & 17 & $5.9 \pm 4.2$ & $9.8 \pm 6.2$ & -2.165 & 0.038 \\
\hline
\end{tabular}

\section{Correlation between SUVmax and survival}

The highest SUVmax of all lesions was divided into seven groups as follows: $2-4,4-6,6-8,8-10,10-12$, $12-14$, and $>14$. According to the median survival time of patients in each group (Table 3.1) and the survival curve (Fig. 2.1), SUVmax $=6$ was determined as the appropriate cut-off value. The median survival time of the patients with SUVmax $>6$ in all lesions was significantly lower than that of those with SUVmax $\leq 6$ (16.7 months [95\% Cl: 11.691-21.709] vs. 24.3 months [95\% Cl: 18.32-29.02], log rank value $=5.034, p$ $=0.025)$ (Fig. 3.1).

Table 3.1

Correlation between the highest SUVmax of all lesions and survival

\begin{tabular}{|lllll|}
\hline SUV group & cases & median survival time & $\begin{array}{l}95 \% \mathrm{Cl} \\
\text { lower limit }\end{array}$ & $\begin{array}{l}95 \% \mathrm{Cl} \\
\text { Upper limit }\end{array}$ \\
\hline $2-4$ & 15 & 30.0 & 7.118 & 52.815 \\
\hline $4-6$ & 21 & 24.3 & 9.945 & 38.588 \\
\hline $6-8$ & 35 & 18.1 & 13.044 & 23.089 \\
\hline $8-10$ & 28 & 23.0 & 11.827 & 34.106 \\
\hline $10-12$ & 15 & 16.5 & 1.318 & 31.615 \\
\hline $12-14$ & 10 & 18.0 & 3.814 & 32.119 \\
\hline 14 & 33 & 12.0 & 6.787 & 17.146 \\
\hline
\end{tabular}

The SUVmax of the primary lung lesions was divided into eight groups as follows: $0-2,2-4,4-6,6-8,8-$ $10,10-12,12-14$, and $>14$. According to the median survival time of the patients in each group (Table 3.2) 
and the survival curve (Fig. 2.2), SUV = 6 was determined as the appropriate cut-off value. Patients whose primary lung lesions showed SUVmax $>6$ had significantly lower median survival time than those showed SUVmax $\leq 6$ (16.4 months [95\% Cl: 12.465-20.335] vs. 24.3 months [95\% Cl: 18.685-29.848], log rank value $=5.849, p=0.016)$ (Fig. 3.2)

Table 3.2

Correlation between the SUVmax of primary lung lesions and survival

\begin{tabular}{|lllll|}
\hline SUV group & cases & median survival time & $\begin{array}{l}95 \% \mathrm{Cl} \\
\text { lower limit }\end{array}$ & $\begin{array}{l}95 \% \mathrm{Cl} \\
\text { Upper limit }\end{array}$ \\
\hline $0-2$ & 5 & 33.4 & 21.806 & 44.994 \\
\hline $2-4$ & 26 & 23.3 & 16.179 & 30.421 \\
\hline $4-6$ & 28 & 23.1 & 17.349 & 28.784 \\
\hline $6-8$ & 29 & 18.6 & 8.544 & 28.656 \\
\hline $8-10$ & 25 & 20.4 & 12.642 & 28.092 \\
\hline $10-12$ & 11 & 13.5 & 5.698 & 21.235 \\
\hline $12-14$ & 9 & 18.0 & 0 & 37.056 \\
\hline$\square 14$ & 24 & 12.0 & 6.779 & 17.154 \\
\hline
\end{tabular}

The optimal SUVmax cut-off for both primary lung lesions and all lesions was 6 . This cut-off could better distinguish patients and predict prognosis. The SUV of the primary lung lesions was used for further analysis.

\section{Analysis of factors influencing survival}

Univariate analysis showed that survival was correlated with sex, size of the primary lung cancer lesion ( $\leq$ $3 \mathrm{~cm}$ vs. $>3 \mathrm{~cm}$ ), EGFR mutation, the SUVmax of the primary lung cancer lesion ( $\leq 6 \mathrm{vs} .>6$ ), and treatment line (Table 4). Specifically, the survival time was significantly longer among female patients $(p=0.021)$, those with EGFR mutation-positive tumors $(p=0.000)$, size of the primary lung lesions $<3 \mathrm{~cm}(p=0.006)$, SUVmax of the primary lung lesions $\leq 6(p=0.016)$, and second-line treatment or above $(p=0.001)$. However, survival was not correlated with age, loss of weight, smoking status, PS score, histology, TNM stage, metastatic lesions, and number of metastases $(p>0.05)$. 
Table 4

Results of univariate analyses by log-rank test:factors influencing effect on survival

\begin{tabular}{|c|c|c|c|c|c|c|c|}
\hline Variable & & No. & $\begin{array}{l}\text { median } \\
\text { survival } \\
\text { time(m) }\end{array}$ & $\begin{array}{l}95 \% \mathrm{Cl} \\
\text { lower } \\
\text { limit }\end{array}$ & $\begin{array}{l}95 \% \mathrm{Cl} \\
\text { Upper } \\
\text { limit }\end{array}$ & $F\left(X^{\wedge} 2\right)$ & $\begin{array}{l}P \\
\text { value }\end{array}$ \\
\hline \multirow[t]{3}{*}{ age } & $\geq 65$ & 71 & 23.4 & 14.445 & 32.355 & 0.194 & 0.660 \\
\hline & 865 & 86 & 18.0 & 12.400 & 23.733 & & \\
\hline & male & 98 & & 12.485 & 20.448 & 5.304 & 0.021 \\
\hline \multirow[t]{2}{*}{ sex } & & & 16.5 & & & & \\
\hline & female & 59 & 23.1 & 15.772 & 30.362 & & \\
\hline \multirow[t]{2}{*}{ smoking history } & yes & 63 & 16.7 & 10.506 & 22.894 & 3.104 & 0.078 \\
\hline & no & 94 & 21.0 & 14.055 & 27.945 & & \\
\hline \multirow[t]{2}{*}{ weight loss } & yes & 22 & 16.7 & 11.346 & 22.054 & 1.829 & 0.176 \\
\hline & no & 135 & 21.4 & 16.405 & 26.461 & & \\
\hline \multirow[t]{2}{*}{ PS score } & $0-1$ & 146 & 20.4 & 15.544 & 25.189 & 3.089 & 0.079 \\
\hline & $\geq 2$ & 11 & 2.5 & 0 & 6.022 & & \\
\hline \multirow[t]{2}{*}{ lesion size } & $\geq 3 \mathrm{~cm}$ & 95 & 16.4 & 12.265 & 20.535 & 7.597 & 0.006 \\
\hline & $\nabla 3 \mathrm{~cm}$ & 61 & 23.3 & 15.912 & 30.688 & & \\
\hline \multirow[t]{2}{*}{ histology } & squamous & 20 & 16.4 & 11.838 & 20.895 & 0.600 & 0.439 \\
\hline & $\begin{array}{l}\text { Non- } \\
\text { squamous }\end{array}$ & 137 & 20.1 & 15.398 & 24.802 & & \\
\hline \multirow[t]{2}{*}{ EGFR mutation } & yes & 51 & 29.5 & 25.700 & 33.366 & 18.707 & 0 \\
\hline & no & 106 & 14.0 & 10,337 & 17.730 & & \\
\hline \multirow[t]{2}{*}{ stage } & M1a & 38 & 21.0 & 13.503 & 28.497 & 0.000 & 0.984 \\
\hline & M1b & 119 & 18.6 & 13.352 & 23.848 & & \\
\hline \multirow[t]{2}{*}{ bone metastasis } & yes & 99 & 18.1 & 11.990 & 24.144 & 0.003 & 0.954 \\
\hline & no & 58 & 21.5 & 18.493 & 24.507 & & \\
\hline \multirow[t]{2}{*}{ adrenal metastasis } & yes & 32 & 12.8 & 6.379 & 19.221 & 2.964 & 0.085 \\
\hline & no & 125 & 21.5 & 17.495 & 25.505 & & \\
\hline
\end{tabular}




\begin{tabular}{|c|c|c|c|c|c|c|c|}
\hline \multirow[t]{2}{*}{ Variable } & & \multirow[t]{2}{*}{ No. } & \multirow{2}{*}{$\begin{array}{l}\text { median } \\
\text { survival } \\
\text { time(m) }\end{array}$} & \multirow{2}{*}{$\begin{array}{l}95 \% \mathrm{Cl} \\
\text { lower } \\
\text { limit }\end{array}$} & $95 \% \mathrm{Cl}$ & \multirow[t]{2}{*}{$F\left(X^{\wedge} 2\right)$} & \multirow{2}{*}{$\begin{array}{l}P \\
\text { value }\end{array}$} \\
\hline & & & & & limit & & \\
\hline \multirow[t]{2}{*}{ pleura metastasis } & yes & 49 & 21.0 & 17.114 & 24.886 & 0.000 & 0.993 \\
\hline & no & 106 & 18.6 & 11.776 & 25.424 & & \\
\hline \multirow[t]{2}{*}{ lymphnode metastasis } & yes & 102 & 16.7 & 11.112 & 22.288 & 3.705 & 0.054 \\
\hline & no & 55 & 23.3 & 13.529 & 33.071 & & \\
\hline \multirow[t]{2}{*}{ liver metastasis } & yes & 18 & 10.8 & 6.434 & 15.166 & 0.684 & 0.408 \\
\hline & no & 139 & 21.4 & 17.689 & 25.178 & & \\
\hline \multirow[t]{2}{*}{ intrapulmonary metastasis } & yes & 52 & 20.1 & 12.850 & 27.350 & 2.083 & 0.149 \\
\hline & no & 105 & 19.0 & 12.930 & 25.070 & & \\
\hline \multirow[t]{2}{*}{ metastatic numbers } & $\geq 2$ & 78 & 16.4 & 9.837 & 22.963 & 0.003 & 0.955 \\
\hline & $₫ 2$ & 77 & 21.5 & 17.370 & 25.630 & & \\
\hline \multirow[t]{2}{*}{ SUV of primary lung lesion } & $\leq 6$ & 98 & 24.3 & 18.685 & 29.848 & 5.849 & 0.016 \\
\hline & $>6$ & 59 & 16.4 & 12.465 & 20.335 & & \\
\hline \multirow[t]{2}{*}{ treatment status } & first-line & 76 & 14.0 & 10.412 & 17.654 & 12.070 & 0.001 \\
\hline & $\begin{array}{l}\text { second- } \\
\text { line }\end{array}$ & 81 & 28.1 & 21.399 & 34.801 & & \\
\hline \multirow{2}{*}{$\begin{array}{l}\text { SUV of metastatic lesion } \\
\text { higher than primary } \\
\text { lunglesion }\end{array}$} & yes & 44 & 18.4 & 6.380 & 30.420 & 0.407 & 0.523 \\
\hline & no & 113 & 20.1 & 15.810 & 24.390 & & \\
\hline
\end{tabular}

The Spearman's correlation analysis showed an interaction between SUV of the pulmonary lesion and lesion size ( $R$-value $=0.578, P<0.001)$. Therefore, only four factors were included in Cox multivariate analysis: sex, EGFR mutation, SUV of the primary lung lesion, and treatment line. In multivariate analysis, survival was still correlated with sex $(p=0.026)$, EGFR mutation $(p=0.001)$, SUVmax of the primary lung cancer lesion $(\leq 6$ vs. $>6)(p=0.036)$, and treatment line $(p=0.029)$. Patients with SUVmax $\leq 6$ had a mortality risk of $0.651(95 \% \mathrm{Cl}: 0.436-0.972$, Wald value, $4.400, p=0.036)$ compared with those with SUVmax $>6$.

\section{Discussion}

The evaluation of SUV is intuitive and convenient, but whether SUVmax provides additional prognostic value in addition to the TNM stage remains to be explored[12,13,21]. Previous studies showed that higher SUVmax was associated with worse overall survival, but these studies were mostly based on early stage 
lung cancer[4, 6, 18,22], and results have been conflicting. Furthermore, some studie[12, 21, 23]reported that SUV has no prognostic value independent of the TNM stage in advanced lung cancer. Hoang et al[23]. suggested that SUV cannot predict prognosis in patients with advanced lung cancer (stage IIIB and stage IV) because a continuous increase in SUV does not increase the risk of mortality. In contrast, Paesmans et al[21]. reported that SUV is an independent predictor for patients with stage I-III NSCLC but not for those with stage IV disease. The possible reason for this is that the median survival for stage IV patients is only 12 months. The short survival period resulted in failure to identify any independent prognostic value for SUVmax. Our study confirmed that SUV is a prognostic factor for overall survival in advanced lung cancer patients. Our analysis showed that patients with EGFR mutations accounted for $32.5 \%$ of the patients in our study, and the development of targeted therapy has resulted in significantly prolonged survival in patients with advanced NSCLC $[24,25]$. A high SUVmax indicates a worse severity of malignancy and more aggressive tumor proliferation[6, 26]. Because of these aggressive biological behavioral characteristics, patients with a high SUVmax lose the chance to receive second-line treatment. Thus, the benefit from a variety of treatments and the overall survival in these patients is limited[27].Patients who received first-line treatment had a significantly greater SUV than did those who received second-line treatment or more. The results appear to support this view. Studies on the optimal SUV threshold have also reported inconsistent findings $[2,4,6,13,15,19,28,29]$. In this study, the median survival time and survival curves showed that an SUV of 6 was the optimal cut-off value. Meanwhile, Detterbeck et al. suggested that the correlation between SUV and prognosis is a gradual association without an absolute threshold[30].

With respect to the association between SUVmax and clinical factors, our study found that the highest SUVmax of all lesions significantly increased among patients with loss of weight, primary lung cancer lesion size $>3 \mathrm{~cm}$, and number of metastases $\geq 2$. The higher SUV may indicate more severe malignancy, shorter doubling time[6],and more aggressive invasion[17, 26]. This would lead to a larger malignant lesion[2, 4, 8, 11, 14, 26],more extensive organ involvement and more obvious weight loss[2, 3, 31].

In addition, we also found that the SUVmax of all lesions was markedly higher in patients with squamous cell carcinoma than in patients with non-squamous-cell carcinoma. Previous studies showed that SUV was correlated with histology, with the SUV of squamous cell carcinoma being greater than that of adenocarcinoma[2, 8, 10,11, 21, 32]. In contrast, we found no significant difference in the histology and SUV of primary lung cancer lesions. This may be because squamous carcinoma is a central lung cancer and thus lymph node enlargement is common and more likely to form in the cavity, mixed with obstructive pneumonia and atelectasis. Previous studies also showed that the SUV of poorly differentiated malignant lesions was higher than that of well-differentiated tumors[8, 29]. We could not perform a more in-depth analysis in this study because the number of cases of squamous cell carcinoma was less than that of adenocarcinoma. Further studies with a well-balanced histology distribution are needed to evaluate the correlation between tumor histological types and SUV.

Our study has some limitations that should be considered. First, it is a retrospective study conducted only in a single center. Therefore, further studies with a larger sample size and conducted in a multicenter setting are needed to confirm our findings. Second, the estimated SUV of primary lung cancer lesions was influenced by various factors; including the patient's blood glucose levels, imaging time, reconstruction 
method, maximum absorption value, and analysis by the same observer. However, it is impossible to guarantee that all patients will receive PET/CT imaging under the same conditions in the real world. Third, the inclusion of only patients who received treatment may have led to selection bias.

\section{Conclusion}

We found that pretreatment SUV of the primary lung lesion on PET/CT is significantly associated with prognosis in patients with advanced NSCLC. SUV of the primary lung lesions had a stronger relationship with survival than the highest SUVmax among all lesions. The optimal SUV cut-off was 6 , and patients with SUVmax $>6$ had a significantly worse prognosis than did those with an SUVmax $\leq 6$. Thus, further prospective studies are warranted to confirm the feasibility of PET/CT imaging-guided treatments in patients with stage IV NSCLC.

\section{Abbreviations}

ALK, anaplastic lymphoma kinase; $\mathrm{Cl}$, confidence intervals; EGFR, epidermal growth factor receptor; FDG, fluorodeoxyglucose; HR, Hazard ratios; IASCL, International Association for the Study of Lung Cancer; NSCLC, non-small-cell lung cancer; PET/CT, positron emission tomography/computed tomography; PS, performance status; ROS1, c-ros oncogene 1 receptor tyrosine kinase; SUV, standardized uptake value; TKI, tyrosine kinase inhibitor; TMN, tumor/node/metastasis staging system

\section{Declarations}

\section{Ethics approval and consent to participate}

The study was approved by Ethic Committee of Peking Union Medical College Hospital and concent for publication. All patients provided written informed consent for the collection of their clinical data.

\section{Consent for publication}

All authors read and approved the final version.

\section{Competing interests}

The authors declare that they have no competing interests.

\section{Funding}

This study was supported by the "13th Five-Year" National Science and Technology Major Project for New Drugs (No. 2019ZX09734001-002), and CAMS Innovation Fund for Medical Sciences (CIFMS) (to MZW) (Grant No. 2018-12M-1-003). They are just funders without other roles.

\section{Authors' contributions}

XLQ and HGL wrote the manuscript. WZ, JZ, MJC, ZHZ, YX, and MZW edited the final version. 


\section{Acknowledgements}

Not Applicable

\section{Availability of data and materials}

The datasets used and analyzed during the current study available from the corresponding author on reasonable request.

\section{References}

1. Siegel RL, Miller KD, Jemal A. Cancer statistics, 2019. CA Cancer J Clin 2019; 69: 7-34.

2. Ren $\mathrm{H}, \mathrm{Xu} \mathrm{W}$, You $\mathrm{J}$ et al. [Analysis of the Role of PET/CT SUVmax in Prognosis and Its Correlation with Clinicopathological Characteristics in Resectable Lung Squamous Cell Carcinoma]. Zhongguo Fei Ai Za Zhi 2016; 19: 192-199.

3. Paesmans M, Sculier JP, Libert $P$ et al. Prognostic factors for survival in advanced non-small-cell lung cancer: univariate and multivariate analyses including recursive partitioning and amalgamation algorithms in 1,052 patients. The European Lung Cancer Working Party. J Clin Oncol 1995; 13: 12211230.

4. Vansteenkiste JF, Stroobants SG, Dupont PJ et al. Prognostic importance of the standardized uptake value on (18)F-fluoro-2-deoxy-glucose-positron emission tomography scan in non-small-cell lung cancer: An analysis of 125 cases. Leuven Lung Cancer Group. J Clin Oncol 1999; 17: 3201-3206.

5. Paesmans M. [Stage IV NSCLC. Prognostic factors]. Rev Mal Respir 2008; 25: 3s99-106.

6. Usuda K, Saito Y, Sagawa M et al. Tumor doubling time and prognostic assessment of patients with primary lung cancer. Cancer 1994; 74: 2239-2244.

7. Ahuja V, Coleman RE, Herndon J, Patz EF, Jr. The prognostic significance of fluorodeoxyglucose positron emission tomography imaging for patients with nonsmall cell lung carcinoma. Cancer 1998; 83: 918-924.

8. Duan XY, Wang W, Li M et al. Predictive significance of standardized uptake value parameters of FDGPET in patients with non-small cell lung carcinoma. Braz J Med Biol Res 2015; 48: 267-272.

9. Deberardinis RJ, Sayed N, Ditsworth D, Thompson CB. Brick by brick: metabolism and tumor cell growth. Curr Opin Genet Dev 2008; 18: 54-61.

10. Schuurbiers OC, Meijer TW, Kaanders JH et al. Glucose metabolism in NSCLC is histology-specific and diverges the prognostic potential of 18FDG-PET for adenocarcinoma and squamous cell carcinoma. $J$ Thorac Oncol 2014; 9: 1485-1493.

11. Eschmann SM, Friedel G, Paulsen F et al. Is standardised (18)F-FDG uptake value an outcome predictor in patients with stage III non-small cell lung cancer? Eur J Nucl Med Mol Imaging 2006; 33: 263-269.

12. Vesselle $H$, Freeman JD, Wiens $L$ et al. Fluorodeoxyglucose uptake of primary non-small cell lung cancer at positron emission tomography: new contrary data on prognostic role. Clin Cancer Res 2007; 13: 3255-3263. 
13. Sasaki R, Komaki R, Macapinlac $\mathrm{H}$ et al. [18F]fluorodeoxyglucose uptake by positron emission tomography predicts outcome of non-small-cell lung cancer. J Clin Oncol 2005; 23: 1136-1143.

14. Downey RJ, Akhurst T, Gonen M et al. Preoperative F-18 fluorodeoxyglucose-positron emission tomography maximal standardized uptake value predicts survival after lung cancer resection. J Clin Oncol 2004; 22: 3255-3260.

15. Dhital K, Saunders CA, Seed PT et al. [(18)F]Fluorodeoxyglucose positron emission tomography and its prognostic value in lung cancer. Eur J Cardiothorac Surg 2000; 18: 425-428.

16. Jeong HJ, Min JJ, Park JM et al. Determination of the prognostic value of [(18)F]fluorodeoxyglucose uptake by using positron emission tomography in patients with non-small cell lung cancer. Nucl Med Commun 2002; 23: 865-870.

17. Duhaylongsod FG, Lowe VJ, Patz EF, Jr. et al. Lung tumor growth correlates with glucose metabolism measured by fluoride-18 fluorodeoxyglucose positron emission tomography. Ann Thorac Surg 1995; 60: 1348-1352.

18. Cerfolio RJ, Bryant AS, Ohja B, Bartolucci AA. The maximum standardized uptake values on positron emission tomography of a non-small cell lung cancer predict stage, recurrence, and survival. J Thorac Cardiovasc Surg 2005; 130: 151-159.

19. Berghmans T, Dusart M, Paesmans $M$ et al. Primary tumor standardized uptake value (SUVmax) measured on fluorodeoxyglucose positron emission tomography (FDG-PET) is of prognostic value for survival in non-small cell lung cancer (NSCLC): a systematic review and meta-analysis (MA) by the European Lung Cancer Working Party for the IASLC Lung Cancer Staging Project. J Thorac Oncol 2008; 3: 6-12.

20. Sugawara Y, Quint LE, lannettoni MD et al. Does the FDG Uptake of Primary Non-Small Cell Lung Cancer Predict Prognosis?. A Work in Progress. Clin Positron Imaging 1999; 2: 111-118.

21. Paesmans $M$, Garcia $C$, Wong $C Y$ et al. Primary tumour standardised uptake value is prognostic in nonsmall cell lung cancer: a multivariate pooled analysis of individual data. Eur Respir J 2015; 46: 1751-1761.

22. Vesselle H, Pugsley JM, Vallieres E, Wood DE. The impact of fluorodeoxyglucose $F 18$ positronemission tomography on the surgical staging of non-small cell lung cancer. J Thorac Cardiovasc Surg 2002; 124: 511-519.

23. Hoang JK, Hoagland LF, Coleman RE et al. Prognostic value of fluorine-18 fluorodeoxyglucose positron emission tomography imaging in patients with advanced-stage non-small-cell lung carcinoma. J Clin Oncol 2008; 26: 1459-1464.

24. Zhao Y, Liu J, Cai X et al. Efficacy and safety of first line treatments for patients with advanced epidermal growth factor receptor mutated, non-small cell lung cancer: systematic review and network meta-analysis. Bmj 2019; 367: I5460.

25. Franek J, Cappelleri JC, Larkin-Kaiser KA et al. Systematic review and network meta-analysis of first-line therapy for advanced EGFR-positive non-small-cell lung cancer. Future Oncol 2019; 15: 2857-2871.

26. Suzawa N, Ito M, Qiao S et al. Assessment of factors influencing FDG uptake in non-small cell lung cancer on PET/CT by investigating histological differences in expression of glucose transporters 1 and 
3 and tumour size. Lung Cancer 2011; 72: 191-198.

27. Li J, Sasane M, Zhao J et al. Comparative Efficacy of Treatments for Previously Treated Advanced or Metastatic Non-Small-Cell Lung Cancer: A Network Meta-Analysis. Adv Ther 2018; 35: 1035-1048.

28. Paesmans M, Berghmans T, Dusart $M$ et al. Primary tumor standardized uptake value measured on fluorodeoxyglucose positron emission tomography is of prognostic value for survival in non-small cell lung cancer: update of a systematic review and meta-analysis by the European Lung Cancer Working Party for the International Association for the Study of Lung Cancer Staging Project. J Thorac Oncol 2010; 5: 612-619.

29. Tong AN, Han SR, Yan P et al. Prognostic value of FDG uptake in primary inoperable non-small cell lung cancer. Med Oncol 2014; 31: 780.

30. Takigawa N, Segawa Y, Okahara M et al. Prognostic factors for patients with advanced non-small cell lung cancer: univariate and multivariate analyses including recursive partitioning and amalgamation. Lung Cancer 1996; 15: 67-77.

31. de Geus-Oei LF, van Krieken JH, Aliredjo RP et al. Biological correlates of FDG uptake in non-small cell lung cancer. Lung Cancer 2007; 55: 79-87.

32. Boellaard R, Krak NC, Hoekstra OS, Lammertsma AA. Effects of noise, image resolution, and ROI definition on the accuracy of standard uptake values: a simulation study. J Nucl Med 2004; 45: 15191527.

\section{Figures}

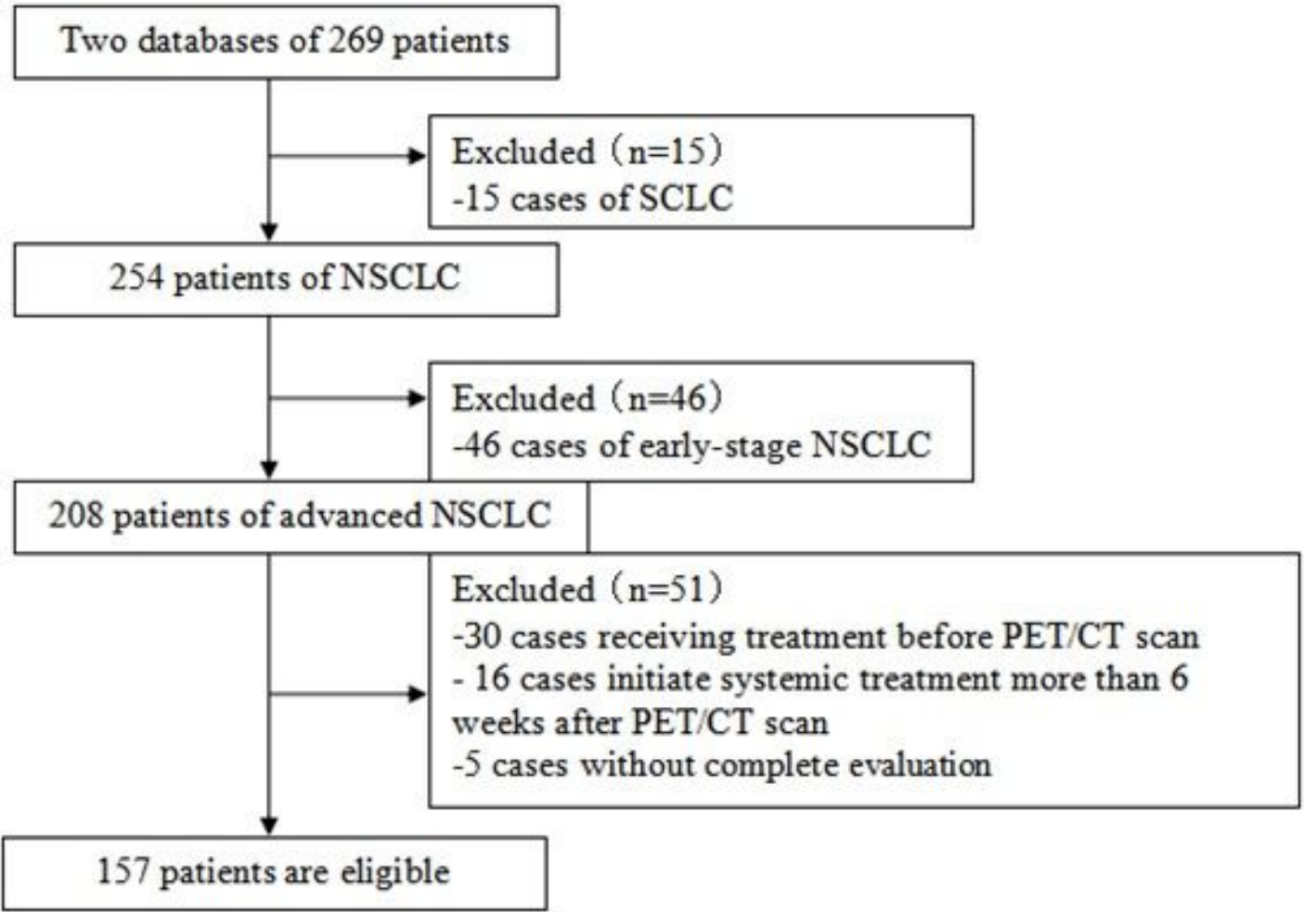

Figure 1 

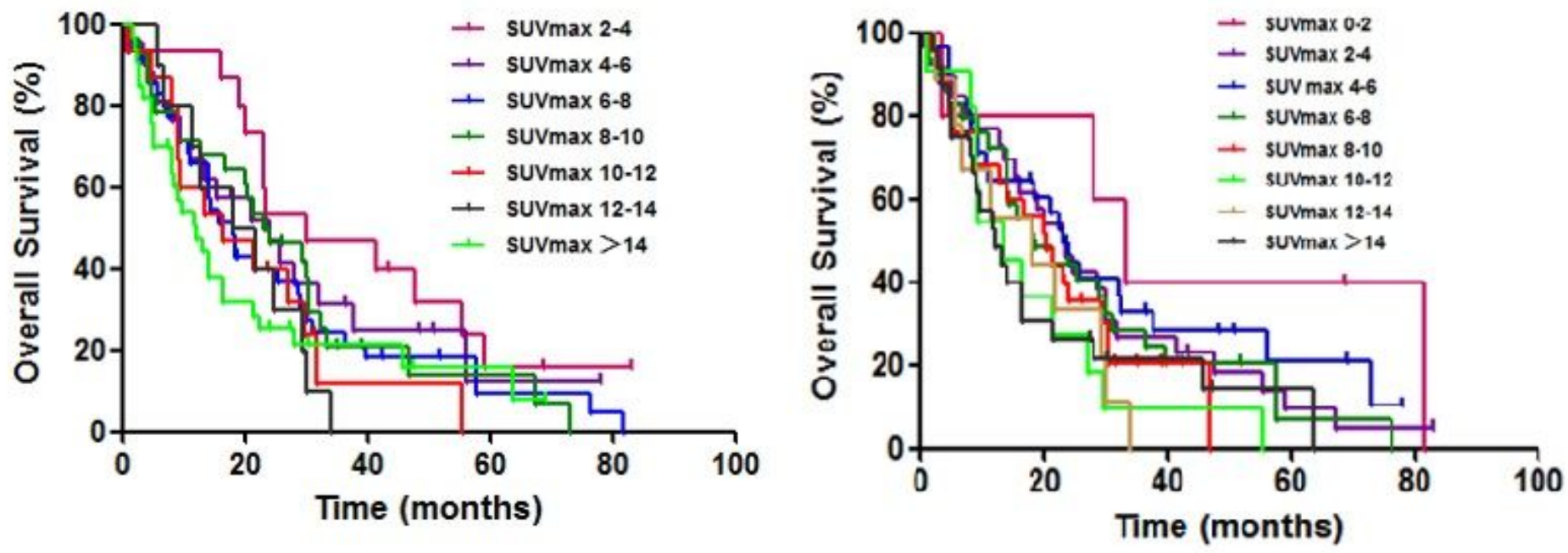

Figure 2

2.1: The Kaplan-Meier survival estimates by SUV groups of primary lung lesions.Analysis time refers to months of all lesions. 2.2: The Kaplan-Meier survival estimates by SUV groups of primary lung lesions.Analysis time refers to months.
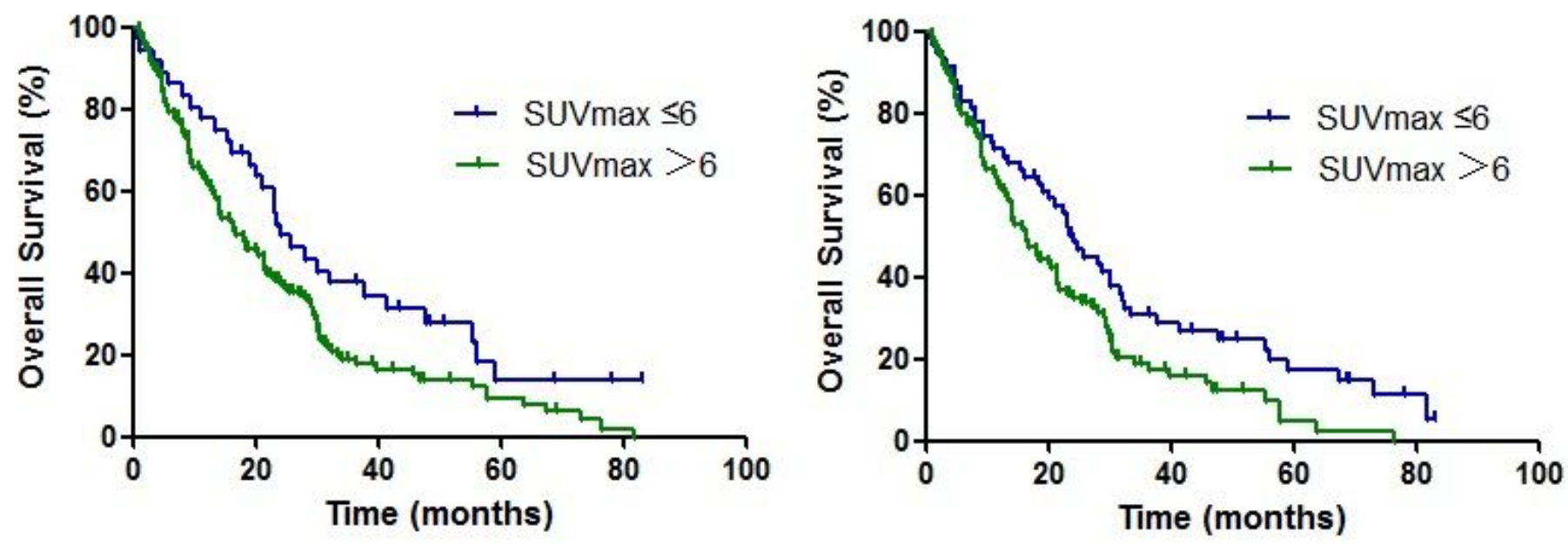

Figure 3

3.1:Survival curves for the two subgroups of the highest SUVmax of all lesions according to the separation

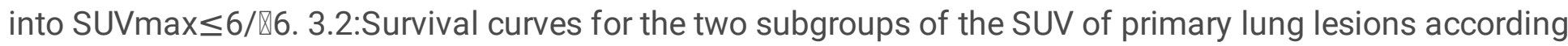

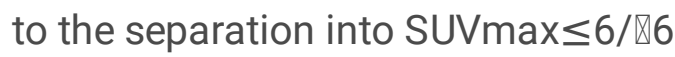

